\title{
Design and Implementation of PCV Device Based on Arduino Board
}

\author{
Huda Farooq Jameel Baban and Suhiar Mohammed Hasan Yaseen \\ Department of Medical Instrumentation Techniques Engineering, Collage of Electrical and \\ Electronic Engineering, Middle Technical University, Baghdad-Iraq. \\ ${ }^{1}$ E-mail: suhairyaseen@yahoo.com.
}

\begin{abstract}
There are many methods which can be used to determine packed red blood cells volume (PCV) value. Some of them are direct and another are indirect methods. However using of the manual ruler to evaluate PCV is the easiest and more economic method which is commonly used as a direct way to determine PCV but with probability of personal errors and plasma trapped. In our search, we have been designed and implemented electronic circuit which is depended on Arduino board to evaluate PCV. The new measuring device is consisted of red light $(600 \mathrm{~nm})$ emitters or diodes to benefit of specified absorbance of this light by erythrocytes (red blood cells) in comparison with lowest absorbance of red light by blood plasma. Then, the transmitted light is received by photocell and photocell's signal is processed by Arduino board. The difference of light intensity between incident and transmitted light after it passes through centrifuged blood sample makes PCV evaluation method reliable on. Seventeen diodes and photocells which are included in this device make determination process of erythrocytes volume to total blood volume easiest and more accurate. Finally using of programmable Arduino board 2560 mega (with determined mathematical equations which are stored in Arduino memory) to calculate and screen PCV and $\mathrm{Hb}$ (hemoglobin) values, it makes analysis of PCV blood reliable and simple treatment.
\end{abstract}

Keywords: PCV, Hematocrit, Arduino board, Microcontroller 2560.

\section{Introduction}

The PCV (packed red cells volume) or hematocrit terms are widely used to describe the volume percentage of erythrocytes to whole blood of blood sample [1]. Normally PCV value is $45 \%$ for men and $40 \%$ for women [2]. Blood consists of red blood, platelets and white blood cells [3]. However the vital rule of red blood cells in transferring life gas (oxygen)[1], makes evaluating of PCV or hematocrit is widely used to diagnosis many disease such as anemia, polycythemia, etc. The most common process to determine PCV includes few steps must be done as illustrated below:

Centrifugation of an anticoagulant blood sample at 10,000 RPM for five minutes is done. Blood will be separated into two layers. PCV is calculated by division of red blood cells height $\left(\mathrm{h}_{\mathrm{Hb}}\right)$ on total sample height $\left(\mathrm{h}_{\text {total }}\right)$ because PCV is the ratio of $h_{H b}$ to $h_{\text {total }}$ [4].

In many labs the PCV is automatically determined by counting the blood cells, as such as PCV values, the numerical values of blood cells count and their $\mathrm{Hb}$ values are listing in reference tables. Measuring of mean volume of red blood and multiplying it by red blood cells count is accurate method which is used by some labs [1]. Other methods are used to determine PCV values are depended on direct or indirect optical analysis of hemoglobin or its derivate compounds spectrophotometry [5]. Depending on errors sources in determination of PCV values, each method of PCV analysis can be evaluated [6]. PCV values which are resulted from manual method are higher than the PCV values of the same samples from automated methods because of plasma trapped in to red blood cells part [7]. The basic concept of this work is depended on selective absorbance of red light by red blood cells part and red light transmittance by blood plasma part. The transmitted light intensity is detected by photocells then Arduino board will processed photocell signal, calculate and screen PCV values.

As shown in Fig.(1) the hematocrit or PCV can be determined by place less than $0.1 \mathrm{ml}$ of blood sample in a heparinized capillary tube. The tube is sealed with artificial clay and centrifuging blood sample at 10,000 (revolutions per minute) for five minutes. This separates the blood sample into layers. The 
volume ratio percent of erythrocytes cells to the total volume of the blood sample gives the PCV value. Since a capillary tube is used, this can be evaluated by measuring the layers lengths of the centrifuged samples instead of layers volumes [4].

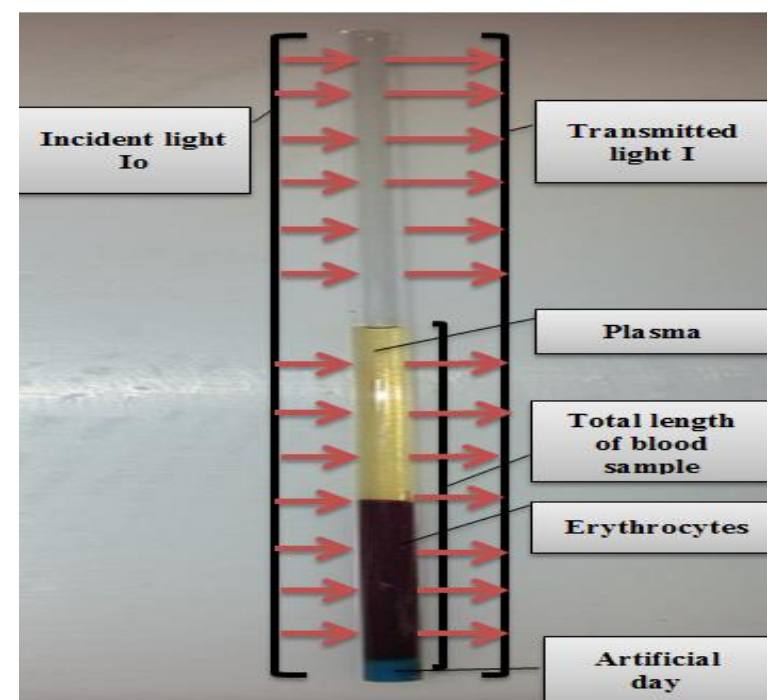

Fig.(1): Pathway of red light which is passed through centrifuged blood sample.

In this search PCV measuring device consists of number of light emitting diodes, at $600 \mathrm{~nm}$, and number of light collecting sensors. These sensors will be active when they sense to high intensity of light after it passes through unabsorbed plasma part. The active signal above is processed by programmable Arduino board and PCV value is reported.

Our device is another work which is depended on light absorbance by packed red blood cells part and light transmittance by plasma part, and both of them are related to lambert beer law [8].

Because of nature of programmable Arduino board which is activated by transmitted light signal, it is more important for us to deal with transmittance (T) which is known as the fraction of light that passes through the sample. This can be determined using the equation below:

\section{Transmittance $(\mathrm{T})=\mathrm{I}_{\mathrm{t}} / \mathrm{I}_{\mathrm{o}}$.}

Where it is the intensity of light after the light beam passes through the capillary tube and $I_{0}$ is intensity of light before the light beam passes through the capillary tube. According to the expression below, transmittance is related to absorption by:

$$
\text { Absorbance }(\mathrm{A})=-\log (\mathrm{T})=-\log \left(\mathrm{I}_{\mathrm{t}} / \mathrm{I}_{\mathrm{O}}\right) \text {. }
$$

\section{Experimental Techniques \\ Measuring device}

This project is based on a family of Arduino boards [9]. Its system provides sets of digital and analog (input/output) pins which are interfaced with extension boards and other circuits. The Arduino board is programmed using very high level language to treat photocells signals. Arduino software (IDE) integrated development environment is used in programming process [10].

As shown in block diagram Fig.(2) and schematic diagram Fig.(3) the practical design of our PCV measuring device, the output part of the Arduino is connected to LCD (liquid crystal display) to display the results. 


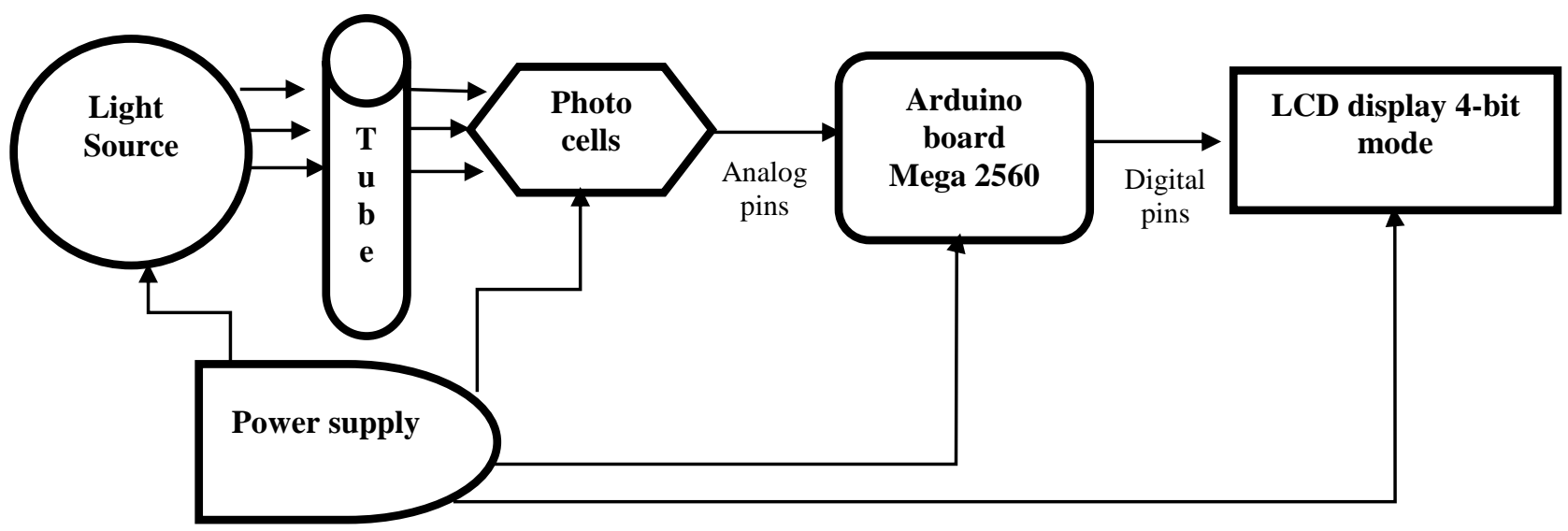

Fig.(2): The block diagram of PCV measuring device.

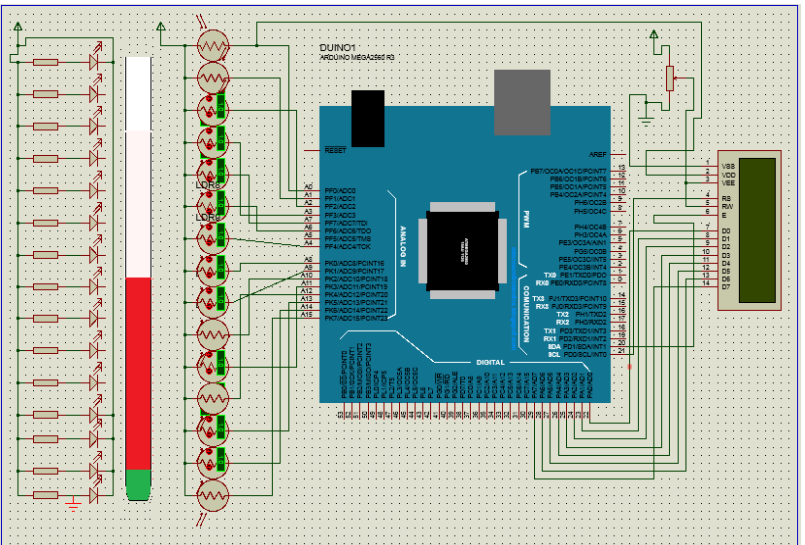

Fig.(3) : The schematic diagram of the PCV measuring device which is done by protos program [11].

The proposal PCV measuring device is included the following parts:

* Arduino board mega 2560 it is a microcontroller which is consisted of almost all parts of a complete computer which are [ROM (read only memory), RAM (random access memory), EEPROM (Electrically Erasable Programmable Read-Only Memory), flash memory to storage code, CPU(central process unit), $16 \mathrm{MHZ}$ crystal oscillator (clock speed), USB connection, Vin pin , GND pin and reset button[9].In this design we are used 15 analog pins (A0-A14) as input to Arduino mega 2560.

* Liquid Crystal Display (LCD)-4 bit mode [12] it is connected to digital pins $(24,26,28$, 30, 32, and 34) from the Arduino mega 2560.

* Light Emitting Diode (LED) it is used as a semiconductor light [13] source which is connected to the power supply.

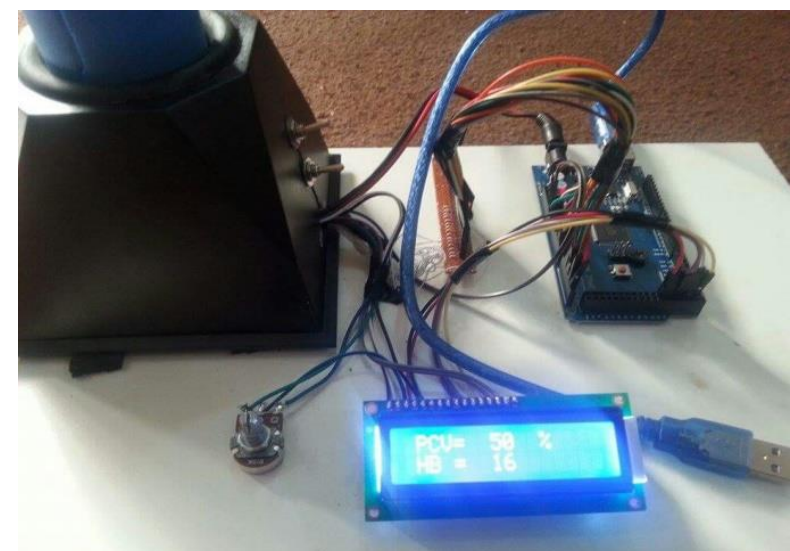

Fig.(4): The result of $\mathrm{PCV}$ and $\mathrm{HB}$ in the device.

\section{Result and Discussion}

After implementation of electronic circuit of PCV measuring device, the program is worked using Arduino software 1.6.4 [14] which is considered very high level language, because it deals with commands that are implemented any program. The Arduino software of this program is shown in Table (1). According to the following steps the program is worked:

1. When the device startup, the program is started at the same time with LCD starting.

2. The program is checked the analog input (serial port) starting from Ao to A14.

3. When the LED is ON, light passes through capillary tube to photocells. Photocells convert energy light to current which is processed by Arduino mega 2560 according to mathematical equations that existed in program and display the results on the LCD as shown in Fig.(4). 
Mathematical equations [4] are stored in Arduino memory to calculate $\mathrm{PCV}$ and $\mathrm{HB}$ are:

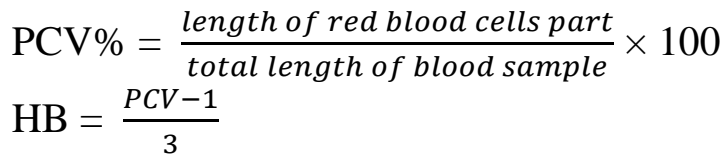

Table (1)

Arduino software.

\begin{tabular}{|c|c|c|}
\hline $\begin{array}{l}\text { \#include <LiquidCrystal.h> } \\
\text { LiquidCrystal lcd(32,30,28,26,24,22); } \\
\text { int a,b,c,d,e,f,g,h,i,j,k,l; } \\
\text { viod setup () } \\
\text { k=0 ; } \\
\text { lcd.begin(16,2 ); } \\
\text { Serial.begin(9600 ); } \\
\text { lcd.setCursor(0,0); } \\
\text { lcd.print("PCV =") } \\
\text { lcd.setCursor(0,1); } \\
\text { lcd.print("HB="); } \\
\text { Serial.print(analogRead(A0)); } \\
\text { Serial.print (" "); } \\
\text { Serial.print(analogRead(A1)); } \\
\text { Serial.print (" "); } \\
\text { Serial.print(analogRead(A2)); } \\
\text { Serial.print ( " "); } \\
\text { Serial.print(analogRead(A3)); } \\
\text { Serial.print ( " "); } \\
\text { Serial.print(analogRead(A4)); } \\
\text { Serial.print ( " "); } \\
\text { Serial.print(analogRead(A5)); } \\
\text { Serial.print (" "); } \\
\text { Serial.print(analogRead(A6)); }\end{array}$ & $\begin{array}{l}\text { Serial.print ( " "); } \\
\text { Serial.print(analogRead(A7)); } \\
\text { Serial.print (" "); } \\
\text { Serial.print(analogRead(A8)); } \\
\text { Serial.print ( " "); } \\
\text { Serial.print(analogRead(A9)); } \\
\text { Serial.print ( " "); } \\
\text { Serial.print(analogRead(A10)); } \\
\text { Serial.print ( " "); } \\
\text { Serial.print(analogRead(A11)); } \\
\text { Serial.print (" "); } \\
\text { Serial.print(analogRead(A12)); } \\
\text { Serial.print (" "); } \\
\text { Serial.print(analogRead(A13)); } \\
\text { Serial.print ( " "); } \\
\text { Serial.print(analogRead(A14)); } \\
\text { Serial.print ( " "); } \\
\text { Serial.print(analogRead(A15)); } \\
\text { Serial.print ( " "); } \\
\text { a=analogRead(A2 ); } \\
\text { b=analogRead(A3 ); } \\
\text { c=analogRead(A4 ); } \\
\text { d=analogRead(A5); } \\
\text { e=analogRead(A6 ); } \\
\text { f=analogRead(A7); }\end{array}$ & 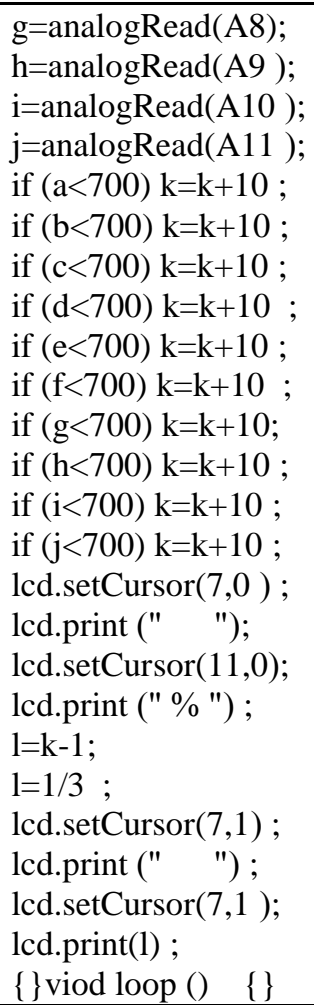 \\
\hline
\end{tabular}

\section{Conclusions}

This search deals with Arduino board (mega 2560) in design of PCV device to processing signal and measure the volume of packed red cells . Some ports of Arduino board (mega 2560) are not use like some of (digital and analog) inputs/ outputs which may be used in future development to change the program or add external memory storage or connect to the computer. The use of Arduino software V.1.6.4 is a professional and power full visual integrated environment (IDE) which Designed specifically for Arduino boards, so it can editing and changing any parameters and variable.

\section{References}

[1] Sembulingam K., Sembulingam P., Assentials of Medical Physiology, Jaypee
Brothers Medical Publisher (P) Ltd, $6^{\text {th }}$. edition, pp.59-88,2010.

[2] Estridge B., Reynolds A., Walters N., Basic Medical Laboratory Techniques, Delmar Thomson Learning $4^{\text {th }}$ edition, pp.125-127, 2000.

[3] Phonphruksa P., Chaichanyut, International Congerss on Biological and Medical Engineers (ICBME), Sigapour, 2002, Vol.14/2 page 878 .

[4] Brian B., M.D., John A.Koepka, M.D, Procedure for determing packed cell volume by the Microhematocrite Method; Clinical and Laboratory Standard Institute, Approved Standard, Carden Jennings Publishing Co., Ltd. Third Edition, Volume 20, Number 18. Laboratory Hematology 7:191-196, 2001. 
[5] Wheeler L. Medical Instrumentation: Application and Design, John Wiley \& Sons, Inc., $4^{\text {th }}$ ed. Hoboken; 498-527, 2010.

[6] Ruckman J., Master of Science Thesis, University of Connecticut, a comparative study of total hemoglobin measurement technology: noninvasive pulse co-oximetry and conventional methods, 2011.

[7] Bosshart M., Stover J., Stocker R., Lars M Asmis L., Feige J., Bosshart et al. BMC Research Notes, 3:65, 2010.

[8] Chang R., Physical Chemistry for the Biosciences. USA: University Science Books, p.521, 2005.

[9] Barrett S, "Arduino Microcontroller processing for everyone", A Publication in the Morgan \& Claypool Publishers series, Third Edition 2013,pp. 12-22.

[10] Monk S., "programming Arduino next step going further with sketches", McGraw -Hill education publishers, first edition, pp. 4-7, 2014.

[11] Lin S. and Huang X., "Advances in computer science environment, conformations and education", Verlag berlin Heidelberg publishers, part V, 2011, pp. 241-243.

[12] Boxall J., "arduio workshop" Publisher: William Pollock, first edition2010, chapter 7 (LCD).

[13] Scele M., "fundamentals of light sources and lasers" Publisher: John Wiley \& Sons, Inc, first edition 2004, page38-47.

[14] Evans B., "beginning Arduino programming with code for most popular microcontroller board in the world", Paul manning publishers, first edition 2011, pp.12-17.

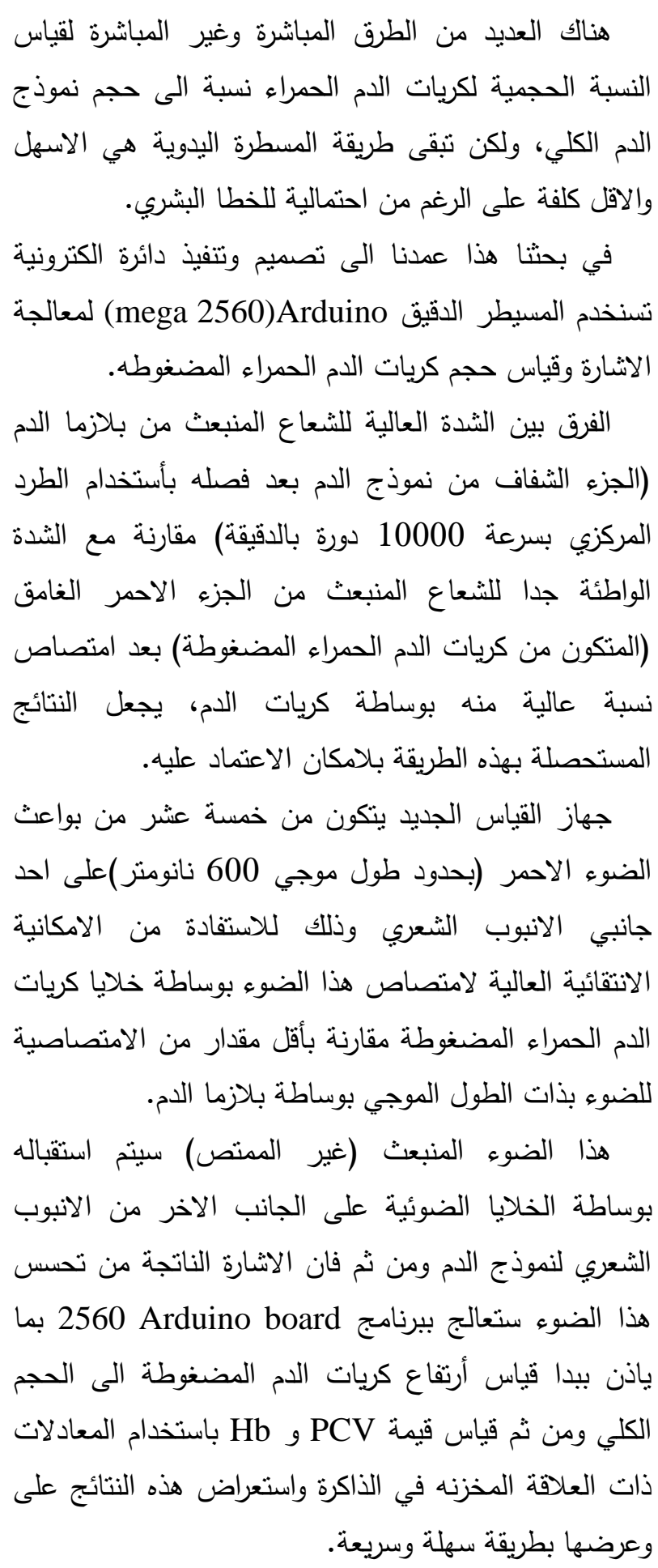

